\title{
Critics claim 'sight-saving' rice is over-rated
}

Nina Schnapp and Quirin Schiermeier, Munich Advocates of agricultural biotechnology are overselling the usefulness of genetically modified Golden Rice in fighting malnutrition, some experts say. The rice is altered to provide extra vitamin $A$, deficiencies of which cause blindness and other illnesses.

The sceptics point out that, in the absence of a balanced diet containing fats that can dissolve vitamin A - and so enable the body to absorb it - the widely vaunted health benefits of the rice are likely to elude the poorest people who eat it.

Golden Rice is genetically engineered to contain provitamin A, the precursor of vitamin A. The commercial rights of the rice are held by Syngenta of Basel, Switzerland, which was formed last year from the merger of the agricultural biotechnology arms of AstraZeneca and Novartis.

Syngenta has agreed to deliver the rice licence-free to scientists and subsistence farmers in developing countries, and the first samples were shipped to a rice research institute in the Philippines in January (see Nature 409, 551; 2001).

Syngenta has stressed that Golden Rice is only a potential solution to vitamin A deficiency and needs "proper investigation".

But others have made stronger claims for it. They include one of the product's inventors, Ingo Potrykus, a former plant scientist at the Swiss Federal Institute of Technology in Zurich. Potrykus writes in the forthcoming issue of In Vitro - Plant (vol. 37 , issue 2) that those opposing use of the rice in developing countries should "be held responsible for the foreseeable unnecessary death and blindness of millions of poor everyyear".

But some nutrition experts are warning about the product's limitations. "Many children go blind even though they consume sufficient provitamin A," says Francis Reed, a biochemist at King's College London. "This is because dietary lipid is in notoriously short supply in many Third World diets."

Vitamin A is present naturally foods suchas eggs, milk and vegetables. But, like many other nutrients, it is a lipid-soluble substance that can only be absorbed by the body if consumed with sufficient fat or oil.

In countries where the consumption of dietary fat is low, Golden Rice is unlikely to benefit health, says Michael Krawinkel, director of the Institute for Nutritional Science at the University of Giessen in Germany, and an expert on nutrition in poor countries.

Potrykus says he is aware of the problem. "The rice does contain some oil," he says. "But it is unclear whether it is enough to entirely absorb the provitamin A." He agrees that further research is necessary to resolve the issue.

"Its biological usefulness and safety have yet to be examined in animal models," says Krawinkel. Tests involving people suffering from vitamin A deficiency are ethically

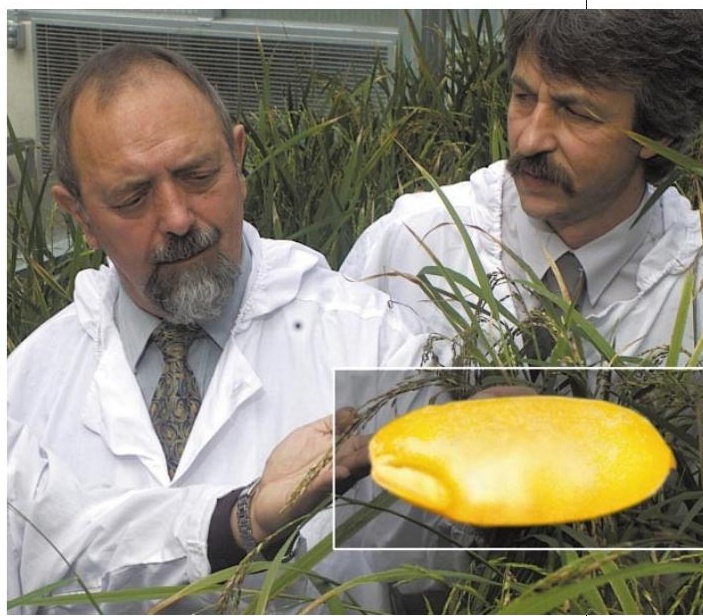

Gold reserve: Potrykus, left with colleague Peter Beyer, admits the rice needs further research.

problematic because the deficiency requires immediate medical treatment that could be readily provided by study teams.

Cultivation of Golden Rice will start later this year in India, China and the Philippines, according to Potrykus. He hopes that sufficient rice will be available by the end of the year to carry out systematic research on its properties and modes of consumption.

But Reed questions whether Golden Rice will ever meet the expectations that have been attached to it. "Rather than merely adding vitamin $A$, the point is to improve poor diets generally," he says.

\section{Plans to reduce acceptable arsenic limit put on hold}

\section{Corie Lok, Washington}

The US Environmental Protection Agency (EPA) is halting plans to lower the standard for arsenic in drinking water from 50 parts per billion (ppb) to $10 \mathrm{ppb}$, citing a lack of scientific evidence to justify the change.

The EPA says it will now seek an independent review of the science behind the lower standard, despite a 1999 study conducted by the National Academy of Sciences (NAS) at the EPA's request. In its report, the NAS recommended that the 50 -ppb standard, set in 1942, be lowered "as promptly as possible" to an unspecified number.

A 10 ppb limit on inorganic arsenic is already recommended by the World Health Organization and by a 1998 directive from the European Union.

"Certainly the standard should be less than $50 \mathrm{ppb}$, but the scientific indicators are unclear as to whether the standard needs to go as low as 10 ppb," said EPA Administrator Christie Whitman in a statement on the cancellation of the 10-ppb standard. She

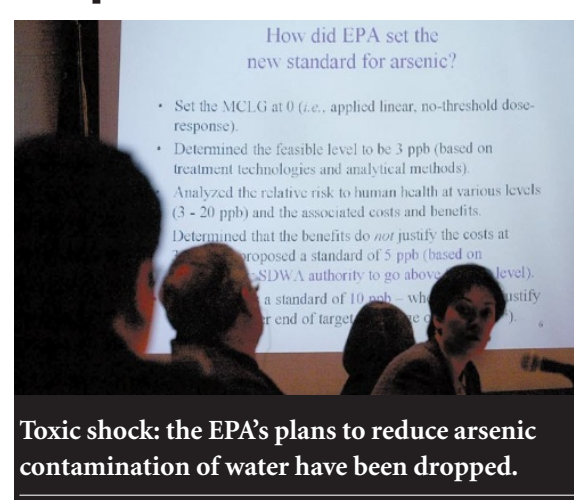

added that a new standard will quickly be devised to take its place.

But the former head of the EPA's water division, Chuck Fox, who was involved in drafting the 10-ppb rule, says that the available data could support a limit of as little as 5 ppb. "There's no question that there's enough science to justify bringing the standard down to $10 \mathrm{ppb}$," he says.

The NAS report found that risks at lowlevel exposures to arsenic had not yet been directly established, but that extrapolation of existing data suggested a cancer risk of between 1 in 100 and 1 in 1,000 for people who regularly consumed water containing $50 \mathrm{ppb}$ of arsenic.

A fresh study in this month's issue of the American Journal of Epidemiology (153, $411-418$; 2001) is one of only a few that directly measure risk for arsenic levels around $10 \mathrm{ppb}$. It found that the risk of urinary tract cancer in Taiwanese farmers was significantly higher when consuming well water containing more than $100 \mathrm{ppb}$ of arsenic compared with those consuming less than $10 \mathrm{ppb}$. But the increased risk among subjects drinking between 10 and $50 \mathrm{ppb}$ was not statistically significant.

The 10-ppb arsenic rule was issued during the Clinton administration's last week in office, and Whitman considers it may have been a rushed decision. Fox disagrees, saying it is based on more than a decade of scientific and economic analysis. t www.nap.edu/books/0309063337/html/index.html www.aje.oupjournals.org/content/vol153/issue5 